\title{
Tribological behaviour diagnostic and fault detection of mechanical seals based on acoustic emission measurements
}

\author{
Hossein TOWSYFYAN ${ }^{1, *}$, Fengshou GU ${ }^{2}$, Andrew D BALL ${ }^{2}$, Bo LIANG ${ }^{2}$ \\ ${ }^{1}$ Institute of Sound and Vibration Research (ISVR), Digital Signal Processing and Control Group, University of Southampton, Southampton \\ SO17 1BJ, UK \\ ${ }^{2}$ School of Computing and Engineering, University of Huddersfield, Huddersfield HD1 3DH, UK \\ Received: 28 June 2018 / Revised: 03 August 2018 / Accepted: 27 August 2018 \\ (C) The author(s) 2018. This article is published with open access at Springerlink.com
}

\begin{abstract}
Acoustic emission (AE) has been studied for monitoring the condition of mechanical seals by many researchers, however to the best knowledge of the authors, typical fault cases and their effects on tribological behaviour of mechanical seals have not yet been successfully investigated. In this paper, AE signatures from common faults of mechanical seals are studied in association with tribological behaviour of sealing gap to develop more reliable condition monitoring approaches. A purpose-built test rig was employed for recording $\mathrm{AE}$ signals from the mechanical seals under healthy and faulty conditions. The collected data was then processed using time domain and frequency domain analysis methods. The study has shown that AE signal parameters: root mean squared (RMS) along with AE spectrum, allows fault conditions including dry running, spring out and defective seal faces to be diagnosed under a wide range of operating conditions. However, when mechanical seals operate around their transition point, conventional signal processing methods may not allow a clear separation of the fault conditions from the healthy baseline. Therefore an auto-regressive (AR) model has been developed on recorded AE signals to classify different fault conditions of mechanical seals and satisfactory results have been perceived.
\end{abstract}

Keywords: tribology; acoustic emission; condition monitoring

\section{Introduction}

A review of sealing technology [1] reiterated the important role of mechanical seals in rotating machines. According to statistics, among the sealing devices of the rotary machines in industrially advanced countries, the usage of mechanical seals is about $90 \%$ of all sealing devices for preventing medium leakage between power input shaft and shell $[2,3]$.

The failure of seals causes direct losses (e.g. leakage and loss of fluid) as well as indirect losses (e.g. downtime and maintenance cost) in industrial applications. Abnormal operating conditions in seals will degrade the machine performance and may cause unexpected sudden failures. A well-known example of this is the disaster of the space shuttle challenger that occurred in 1986, claiming the lives of the all crew members. Subsequent investigations determined the cause of the accident was the failure of an O-ring in the solid rocket booster that was unable to seal a critical gap.

To avoid premature failure of mechanical seals, different non-destructive testing (NDT) methods based upon vibration analysis [4], eddy current [5, 6] and ultrasonic testing $[7,8]$ have been frequently investigated. However, these modalities cannot be effectively used in industry due to their technical limitations. For instance, vibration analysis is influenced more by the shaft speed rather than the frictional state of sealing gap [4]. Another method, eddy current testing, requires modifying the seal structure $[5,6]$.

To overcome the deficiencies of aforementioned

* Corresponding author: Hossein TOWSYFYAN, E-mail: H.Towsyfyan@soton.ac.uk 


\begin{tabular}{|lllll}
\hline \multicolumn{2}{l}{ Nomenclature } & & \\
& & & \\
$G$ & Elastic modulus/Hertzian contact elastic & $h$ & Lubricant film thickness \\
modulus & $x$ & Signal sampled at regular intervals of time \\
$N$ & Dimensionless duty parameter & $c_{1} \ldots c_{\alpha}$ & Weights of the auto-regression model \\
& Number of asperity deformation in any & $\alpha$ & Order of the AR model \\
$V$ & unit area & $\beta$ & Upper limit of sample instances \\
$W$ & Sliding speed & $\varepsilon$ & Residual signal assumed to contain the \\
$\mathrm{f}$ & Contact load in asperity collision & & output \\
& Coefficient of friction & $\mu$ & Viscosity
\end{tabular}

modalities, AE method has been proven to have promising potential for detecting incipient failures of mechanical seals [9-12]. AE measurements have also been proven to be a sensitive indicator of lubrication conditions $[11,13]$. The dependency of AE signatures to the frictional state of lubricated systems gives a strong potential for condition monitoring of mechanical seals (in association with their tribological behaviour) as well as other tribosystems such as journal bearings $[14,15]$, wind turbines [16, 17], gearboxes [18, 19] and rolling element bearings [20, 21].

Based on the theory of face seals' operation, the sealed fluid enters in the sealing gap, see Fig. 1, and distributes itself so that a thin layer of lubricant is formed. Therefore, mechanical seals may experience different tribological regimes i.e. boundary lubrication (BL), mixed lubrication (ML), and hydrodynamic lubrication (HL) regime depending on the operating conditions that is characterised by well-known Stribeck curve, as shown in Fig. 2.

An optimum operational region for mechanical seals would be around the transition point from ML to HL regime, where friction and leakage are minimised $[22,23]$. However, during the seals' operating life, they

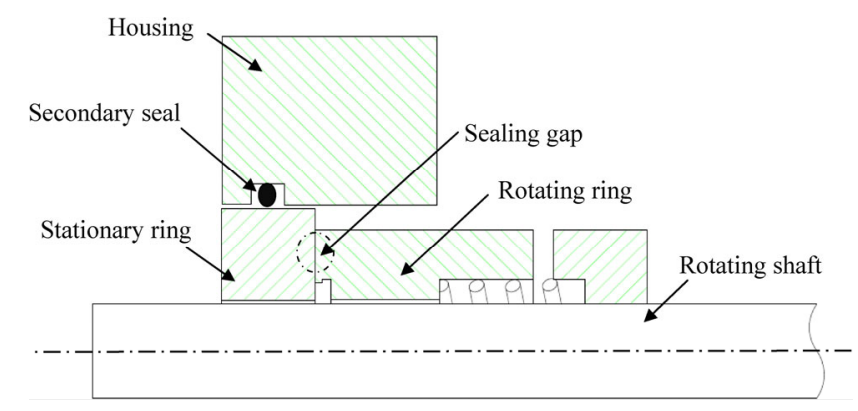

Fig. 1 Schematic illustration of mechanical seals as a tribosystem.

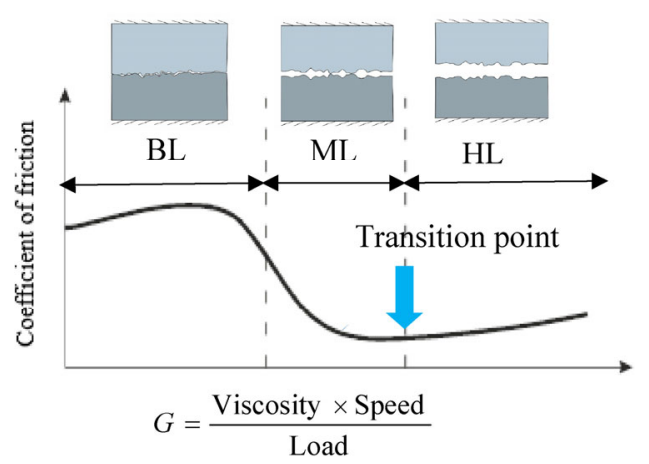

Fig. 2 Stribeck curve.

may face BL regime during start-up and shutdown or due to the fluctuations of pressure and temperature, weak lubrication system, fluid transient vaporisation, abrasives in the sealed fluid and high sealed pressure conditions. BL regime is the unwanted operating regime for mechanical face seals, because it generates excessive wear, dry rubbing and quickly damages to the mating rings.

Based on the operating conditions, three main mechanisms may contribute to AE generation in sliding of mating surfaces, i.e. viscous friction due to shearing of lubricant layers [22, 24, 25], flow induced asperity deformations due to the interaction between surface asperities and fluid flows (that leads to the development of a vibratory behaviour in the surface asperities under HL regime due to dynamic bending and reclamation of surface asperities ) [22] and direct asperity contacts $[22,25-27]$ which are well documented in the literature.

Besides understanding the source mechanism of tribological AEs in mechanical seals, it is also important to characterise them based on AE signal parameters. Several studies demonstrate that AE features extracted 
from $\mathrm{AE}$ waveform in time domain along with spectra analysis is widely used for the purpose of condition monitoring and fault detection in mechanical seals $[4,9-13,22]$. Research has been reported in the literature showing that among the AE signal parameters, a strong relationship exists between the root mean squared (RMS) value of an AE signal (as an indicator of the AE activity) and the multiple interaction of the AE source mechanisms in the sliding contact [27-31]. This correlation has been demonstrated theoretically in the pioneering work of F.Y. Edward et al. [26]. H. Towsyfyan et al. [31] developed a dynamic model based on the multiple interaction of the AE source mechanisms in different tribological regimes to predict the RMS value of an AE signal as summarised in Table 1. This model that has been validated experimentally in Ref. [31] will be used in the remainder of present work to explain the effect of operating conditions (e.g. contact load and rotational speed) on the tribological AEs and thus for interpreting the results of seal monitoring.

Above understandings reveal there is a good correlation between the operating conditions of face seals and RMS value of AE signals. However, as a primary phase for accurate seal monitoring, fault detection of mechanical seals based on tribological behaviour of mating faces has not yet been reported. This is critical in many engineering applications as tribological regimes affect the performance of mechanical seals [32]. This paper attempts to fill this gap and presents an experimental study to demonstrate the competence of $\mathrm{AE}$ measurements for condition monitoring of mechanical seals under wide operating conditions. To introduce a robust AE based approach for accurate seal monitoring, a novel time series analysis will be carried out (as detailed in Section 4) to distinguish different fault condition of mechanical seals operating around their transition point, where conventional signal processing methods may face some challenges as detailed in Section 3.2 to Section 3.4.

\section{Test rig and measurement methods}

Figure 3 shows the general view of the test rig designed and applied for condition monitoring of mechanical seals. A John Crane type 1648 MP pusher cartridge mechanical seal (the rotating ring is made of antimony carbon and the stationary ring is reaction bonded silicon carbide) and a stainless-steel tube formed a pressurised chamber. Details of the test rig, measurement method, and the auxiliary circulating system (to pressurise the chamber and take away the generated frictional heat) have already been published in Ref. [31]. A schematic diagram of the experimental set up along with an overview of the present work is illustrated in Fig. 4.

As it is shown in Fig. 4, the AE sensor (type WD S/N FQ36 with an operating frequency range from $100 \mathrm{kHz}$ to $1 \mathrm{MHz}$ ) has been located on the seal cartridge, to gain the best results. Moreover, the encoder has been synchronized with the AE sensor to allow more accurate investigation on tribological behaviour of mechanical seals.

The experimental work in this research has been

Table 1 The relationship between AE RMS value and seal operating parameter.

\begin{tabular}{ccc}
\hline AE source mechanism & Relationship with AE RMS value \\
Direct asperity contact & $A E R M S \propto W \sqrt{\frac{f N V}{E}}$ \\
Viscous friction & $A E R M S \propto \sqrt{\frac{\mu}{h}}$ & Schematic illustration \\
Flow induced asperity deformations & $A E R M S \propto V \sqrt{\mu N}$
\end{tabular}

Note: $W, f, N, V, E, \mu, h$ are contact load (that is proportional to sealed pressure), coefficient of friction, number of asperity deformations (either due to direct asperity contact or due to flow induced vibrations, see Ref. [31] for details), sliding speed, modulus of elasticity, fluid viscosity, and size of sealing gap (or lubricant film thickness) respectively. 


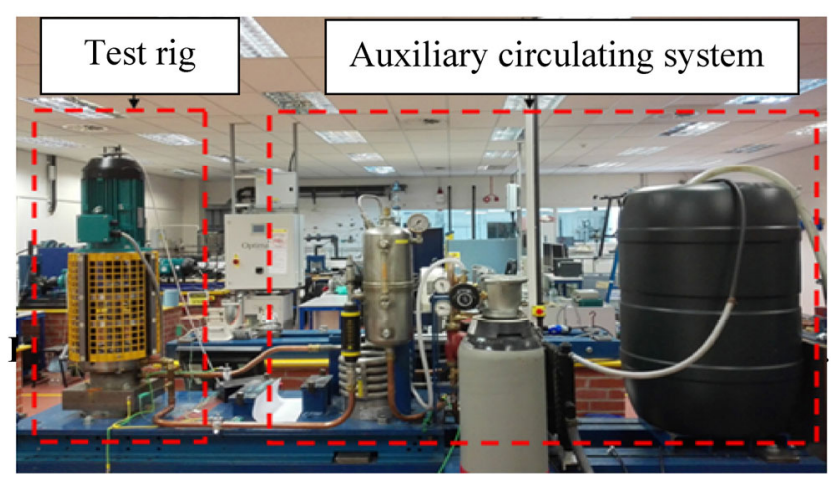

Fig. 3 General view of the mechanical seal test rig [31].

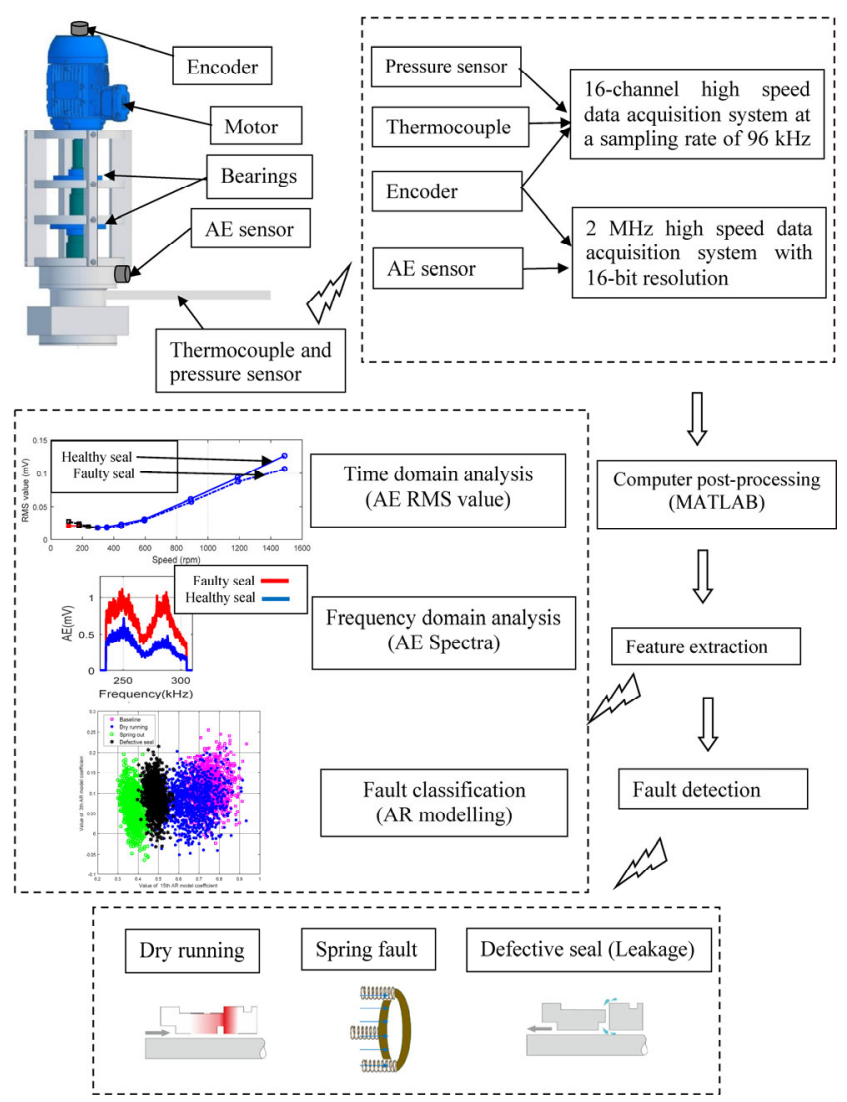

Fig. 4 Schematic illustration of the test rig and experimental fault detection program.

carried out at three different sealed pressures from $2 \pm 0.05$ bar to $8 \pm 0.05$ bar with the step size of three bar. For each load, the data has been recorded at ten different rotational speeds to generate different tribological regimes of mechanical seals.

Three type of common faults in mechanical seals have been investigated i.e. dry running, spring fault, and defective seal as detailed in Section 3.2, Section 3.3, and Section 3.4, respectively.

\section{Results of experimental study of fault detection}

\subsection{Identification of the tribological AEs}

To ensure the reliability of $\mathrm{AE}$ measurements for tribological behaviour diagnostic, a comparative experimental study has been carried out to identify an $\mathrm{AE}$ frequency range that can present the tribological AEs. This experimental study includes three different tests: seal free test, pseudo-stationary test, and transient speed test. To get insight into the identification of tribological AEs from the background noises, the results are analysed in time frequency domain using ShortTime Fourier Transform (STFT).

Seal free test refers to idling of the rig, where the rotating ring was removed from the seal head assembly. As it is observed in Fig. 5, the AE energy concentrated mainly in two frequency ranges between $0-40 \mathrm{kHz}$ (point A) and 100-150 kHz (point B). These frequency ranges are related to background noises (e.g. motor vibration and element contact of bearings) and hence cannot represent tribological AEs.

In the pseudo-stationary test the drive shaft of the test rig was turned manually to generate a slow sliding of seal faces when the seal was not pressurised. Based on Fig. 6, however, in addition to two previous frequency ranges (points $\mathrm{A}$ and $\mathrm{B}$ ), there is another frequency band located in the range of $270 \pm 35 \mathrm{kHz}$ (point C). This frequency range is likely caused by the sliding of seal faces.

To investigate the changes in the amplitude of the aforementioned frequency ranges in different tribological regiemes, a transient speed test was carried

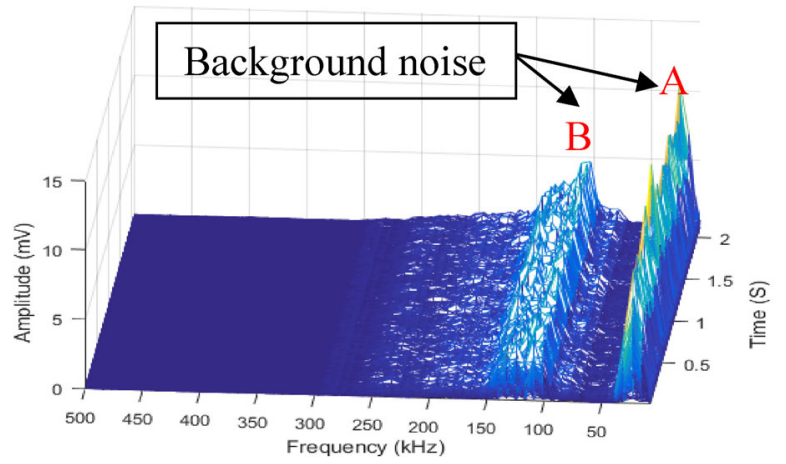

Fig. 5 The spectrogram of AE signals from seal free test (at rotational speed of $1,500 \mathrm{rpm})$. 


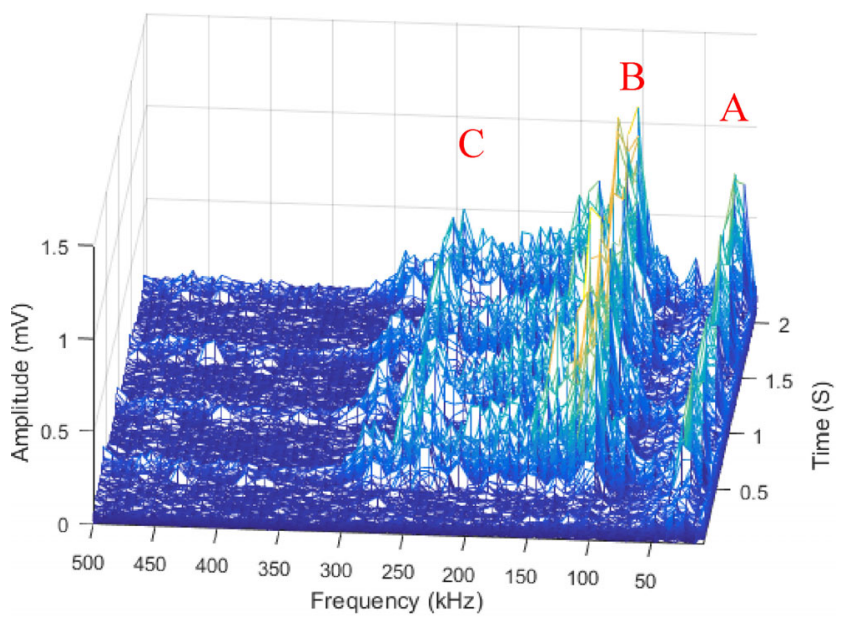

Fig. 6 The spectrogram of AE signals from pseudo-stationary test.

out under 4 bar sealed pressure. As it takes 16 seconds for the motor to reach the speed of $1,500 \mathrm{rpm}$, as illustrated in Fig. 7(a), therefore the load is kept constant during the test and the speed is increased incrementally. Using this method, different tribological regimes are generated during the start up to steady state condition of motor.
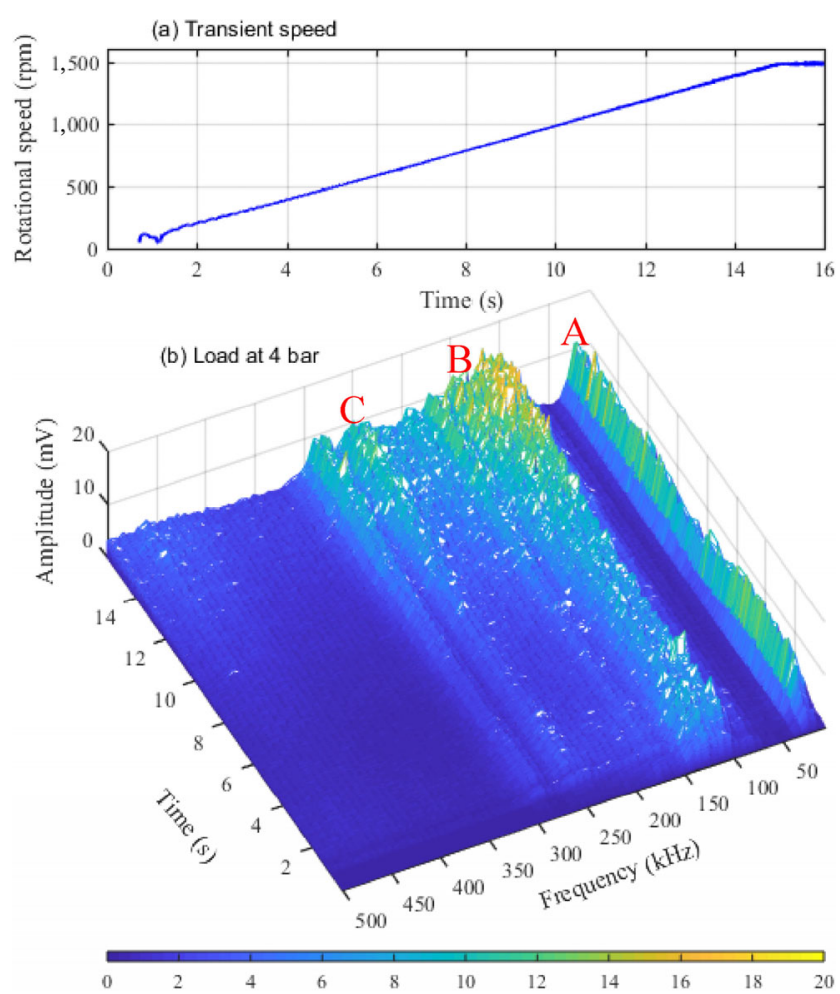

Fig. 7 The transient speed test (a) Motor speed variations; (b) Spectrogram.
As it is evident in Fig. 7(b), the amplitude of two frequency ranges between $0-40 \mathrm{kHz}$ and $100-150 \mathrm{kHz}$ (points A and B) does not change significantly in the seal free test as well as the transient speed test, giving a solid conclusion that the mentioned frequency bands represent noise sources. However, the amplitude of the AE signals in the range of $270 \pm 35 \mathrm{kHz}$ (point C) first increases slightly by the speed increase, indicating that direct asperity collision is a dominant AE source at low rotational speeds of shaft, as described by Eq. (1). By increasing the speed into the ML regime, the amplitude of AE signals (located in the range of $270 \pm 35 \mathrm{kHz}$ ) decreases due to improvement in the lubrication state of sealing gap. Under these conditions, direct asperity contacts are confined by the shearing of lubricant between the mating faces [31], and the RMS value of such AE excitations is prescribed by Eq. (2). As the speed increases gradually, transition into the HL regime occurs and the $\mathrm{AE}$ amplitude of point $C$ increases again, as described by Eq. (3), indicating that dynamic bending and reclamation of surfaces asperities due to fluid flows (flow induced asperity deformation as the main AE source in $\mathrm{HL}$ regime [31]) produce tribological AEs.

This gives good evidence that the mentioned frequency range can correctly present the tribological behaviour of mechanical seals and therefore can be used for accurate seal monitoring. Thus, for the remainder of the paper, a band pass filter was designed using MATLAB codes and applied to AE raw data.

\subsection{Dry running test}

Since mechanical seals are hydrostatically lubricated, running the test rig with no sealed pressure will generate the conditions under which partial dry running occurs (meaning that sealed fluid does not enter in the sealing gap during the experiments), see Ref. [22] for a detailed discussion and more details. Therefore, direct asperity contact happens at low speeds which may cause significant dry rubbing, overheat, and eventually failure of the mating faces.

In Fig. 8, a comparison of AE RMS values is made between the healthy baseline and partial dry running test when sealed pressure is constant and speed increases gradually. The actual rotational speed of shaft 


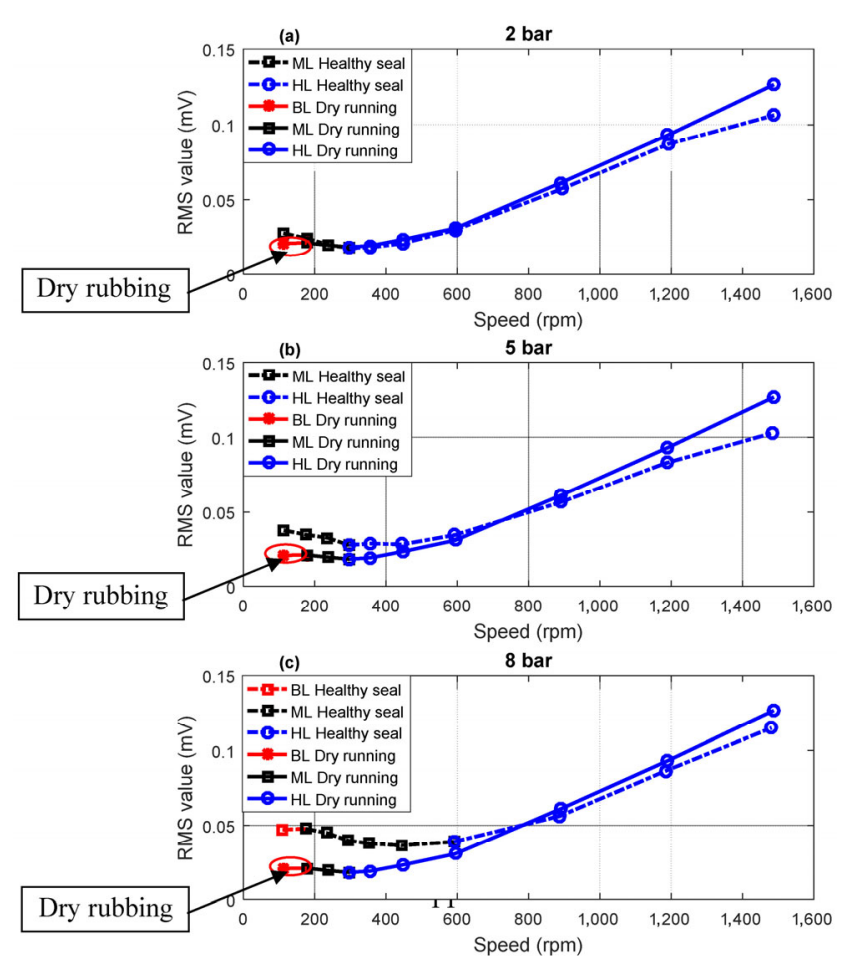

Fig. 8 The AE RMS values for healthy seal and dry running test under different operating conditions (seals are not pressurised in dry running test).

was calculated based on the analysis of encoder data using MATLAB codes.

Figure 8 is tribologically meaningful as different lubrication regimes, characterised by Stribeck curve, are clearly observed. Compared to the baseline test, the level of AE activity in the partial dry running test is lower at low speeds (since the seals are pressurised in the baseline test). This indicates that more asperities come into contact in the healthy baseline and hence a higher level of AE activity is generated due to the contact load increase as depicted by Eq. (1). This could be better understood by considering Fig. 8(b) and Fig. 8(c) (in the regions before transition point), where the AE RMS value from the healthy seal goes up by the sealed pressure increase. As it is evident in Fig. 8(c), the BL regime becomes a dominant tribological regime at the speeds less than $180 \mathrm{rpm}$ for 8 bar sealed pressure. In partial dry running test, however, the $\mathrm{AE}$ RMS value first go up when the speed is increased from $120 \mathrm{rpm}$ into $180 \mathrm{rpm}$, indicating that the $\mathrm{BL}$ regime is a dominant lubrication regime although the seals are not pressurised. This confirms that dry rubbing between the mating faces happens in partial dry running test.

By increasing the speed to the minimum point of the curve, RMS values go down due to improvement in the lubrication condition. To see the interactions between different AE source mechanisms in the ML, i.e. asperity collisions and viscous friction, interested readers may refer to Ref. [31]. As speed increases gradually, transition from ML into the HL regime occurs and RMS values increase again by the speed increase as described by Eq. (3).

However, in some speed and pressure settings, e.g., at the speed of 900 rpm in Figs. 8(a) and 8(b), the AE RMS sees approximately the same values for both healthy and dry running tests. To gain a better distinction of the dry running testing from the healthy baseline, spectral analysis is carried out. This can be implemented by taking into consideration the fact that the useful information provided by the frequency spectra is often the change of frequency components and their amplitudes for different working conditions. Based on Fig. 9, a better separation of the fault condition from the healthy baseline is evident at different speed and pressure settings (except for the speed of $450 \mathrm{rpm}$ in Figs. 8(a) and 8(b)). Therefore, this dependency of AE RMS value along with AE spectra to the lubrication condition of the sealing gap gives good evidence to detect dry running which may lead to the failure of a mechanical seal.

\subsection{Spring fault test}

The springs in seal head assembly may subject to fatigue and corrosion, and hence fail to meet the expected functions. Examination of hundreds of seal failures by different researchers has revealed that most failures are not caused by seal wear out [33, 34]. For many failures the amount of wear is on the order of thousandths of a millimetre whereas the seal is designed for about 3-mm wear before failure [33, 22]. Therefore, it is necessary to study the AE signatures from the sealing gap when other components of the seal head assembly (e.g. spring) fail. In this paper, the spring fault testing was carried out by taking off 2 springs from the seal head assembly (the total number of springs in type $1648 \mathrm{MP}$ mechanical seal is 12), as shown in Fig. 10. It is noted that the spring fault itself is not one of the major failure reasons of mechanical 


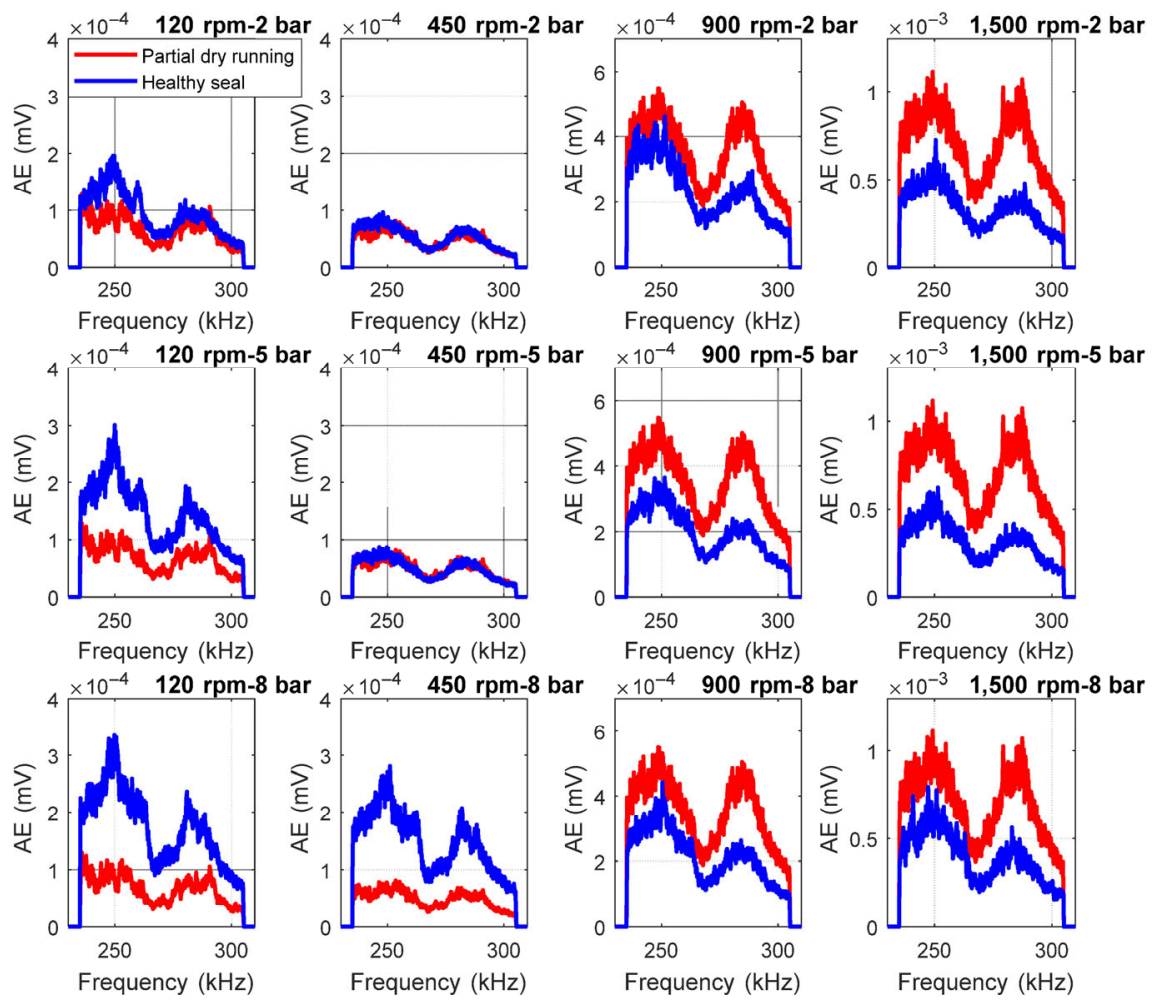

Fig. 9 AE spectra for healthy seal and dry running test under different operating conditions.
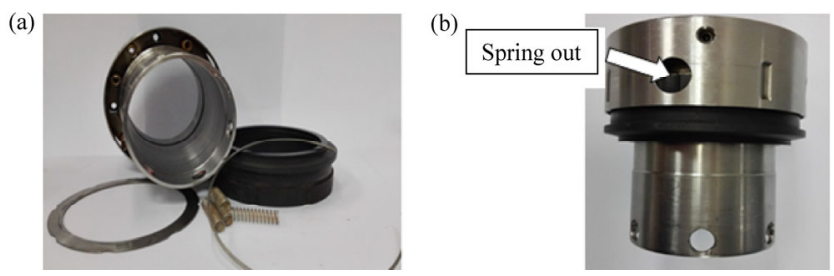

Fig. 10 Seal head assembly in spring fault testing (a) before assembly and (b) after assembly.

seals, however, it can be categorized as 'miscellaneous' failure reasons which are of $15 \%$ of all seal failures [33].

Figure 11 compares AE RMS values for the healthy seal and the spring out test under different speed and pressures settings. As it is evident at the speeds less than $600 \mathrm{rpm}$, the AE RMS values related to the faulty seal see higher level indicating that the AE activity is higher. The most likely reason for increasing the $\mathrm{AE}$ activity is that the sealing gap is uneven with two springs out, therefore there are face regions which see higher contact pressure, hence higher AE level. Consequently, the BL regime becomes a dominant lubrication regime for the experiments have been carried out at low rotational speeds of shaft (i.e. $120 \mathrm{rpm}^{-}$ $240 \mathrm{rpm})$. Moreover, the curvature of the graph related to the spring fault test in the ML regime is not similar to the norm

By increasing the speed into the $\mathrm{HL}$ regime, $\mathrm{AE}$ responses related to the faulty seal become more stable due to the separation of mating faces. The uneven sealing gap also causes that the transition from the ML to the HL regime occurs at higher speeds compared to the healthy baseline.

Therefore this dependency of AE RMS value to the integrity of sealing gap demonstrates the strong potential of proposed approach to investigate the failure of seal head assembly components (e.g. secondary seals, springs, and so on).

In Fig. 12, a comparison of AE spectra amplitudes is made between the spring fault test and the healthy baseline under different speed and pressures settings. As it is evident, the AE spectra allows slightly better separation of the faulty seal from the healthy condition (e.g. at the speed of $900 \mathrm{rpm}$ for different pressure settings).

\subsection{Defective seal test}

In addition to dry running, other mechanisms i.e. 

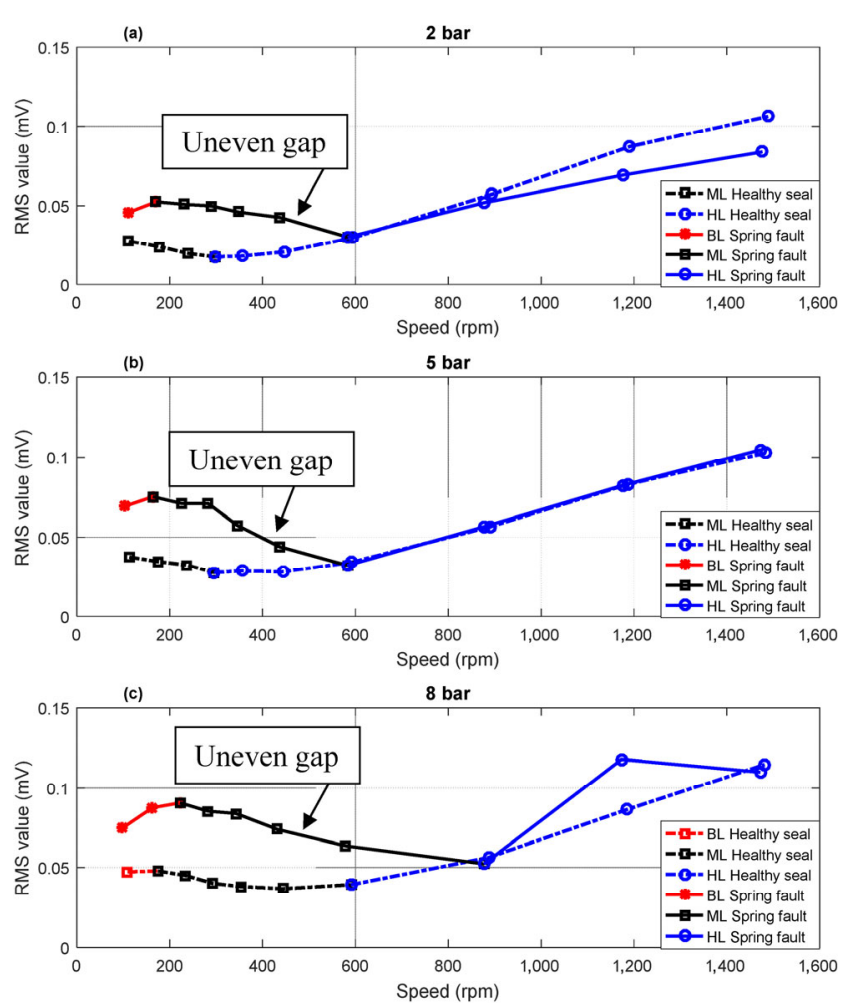

Fig. 11 The AE RMS values in terms of speed for healthy seal and spring out test. abrasives, corrosion or thermal cracks may contribute to damage of the mating faces. To demonstrate the competence of AE measurements to diagnose such failure modes, some radial scratches were made manually on the mating ring by using a diamond dressing tool, as shown in Fig. 13. The smallest defect is only an artificially induced crack (approximately $6 \mathrm{~mm}$ length) and the biggest one has a dimension of approximately $7 \mathrm{~mm} \times 8 \mathrm{~mm}$ as described in Ref. [31].

The defective seal faces reduce the sealing performance of a mechanical seal and may lead to a high value of leakage rate. If the sealed pressure drops to a minimum possible level and spring force is not powerful enough to compensate the opening forces, see Ref. [22] for details, then the negative contact pressure [34] is achieved. This means that opening forces overcome the closing forces and the mechanical seal has failed.

In Fig. 14, a comparison of AE RMS values is made between the baseline test and the defective seal test. It is evident that for the experiments have been conducted at rotational speeds less than $200 \mathrm{rpm}$, an increase in the AE RMS values is observed due to
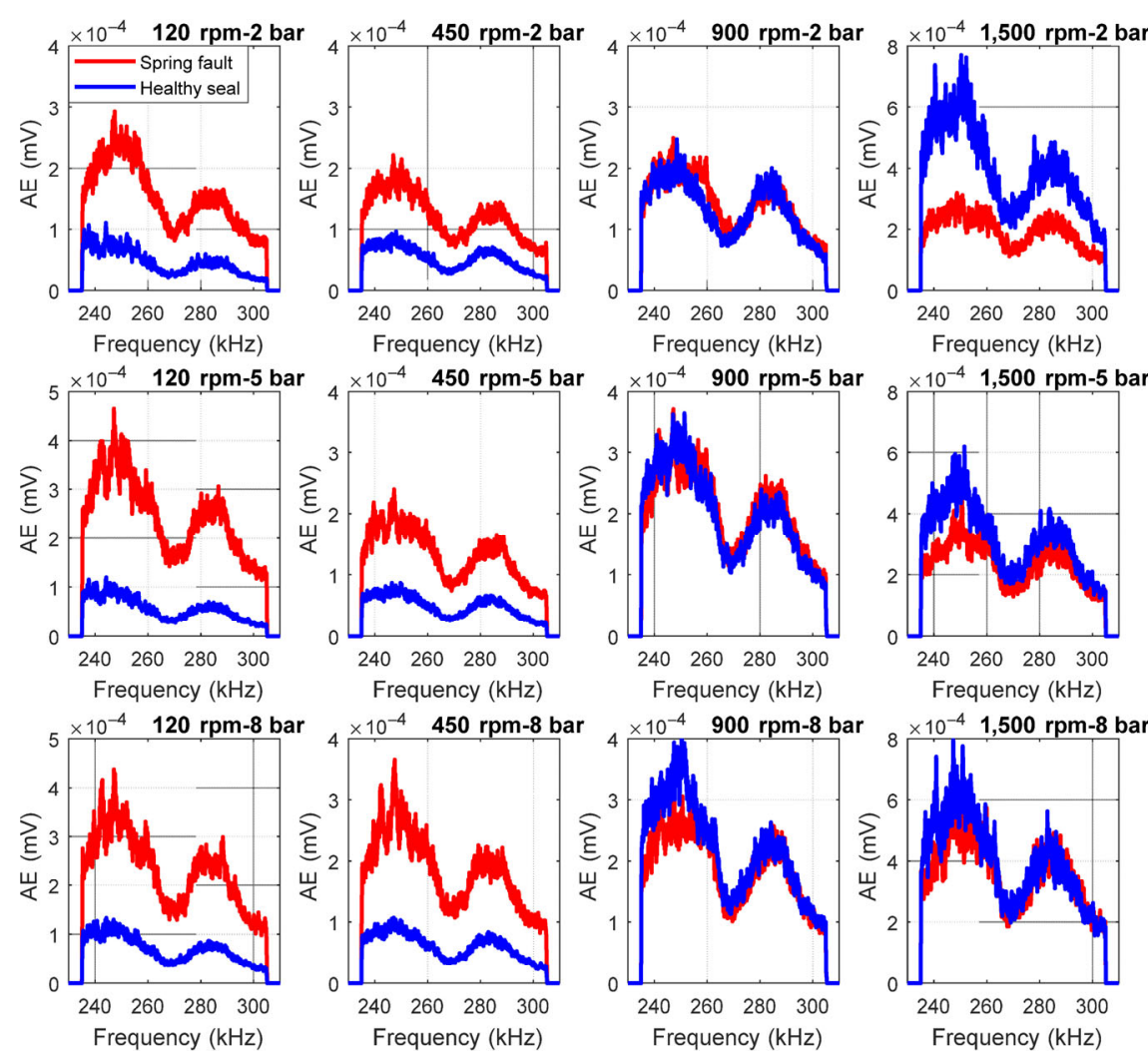

Fig. 12 AE spectra for healthy seal and spring out test under different operating conditions. 
(a)

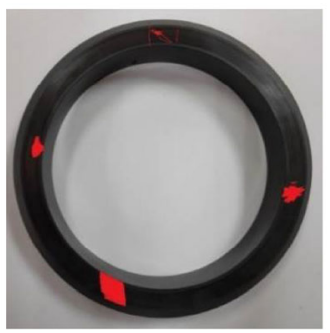

(b)

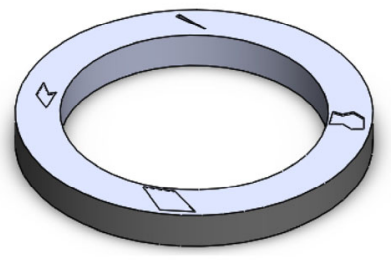

Fig. 13 Defective seal testing: (a) scratches on stationary ring; (b) schematic illustration of artificially induced damages [31].

severe asperity contact in damaged face regions. This trend that is only observed at 8 bar sealed pressure for the healthy baseline, see Fig. 14(c), indicates that sever asperity contact (wear) is a dominant AE source in defective seal testing even at low sealed pressures.

By increasing the speed into the HL region, leakage occurs since seal has failed. Under these conditions, the sealing gap is bigger than the norm and therefore flow induced asperity deformations are not generated
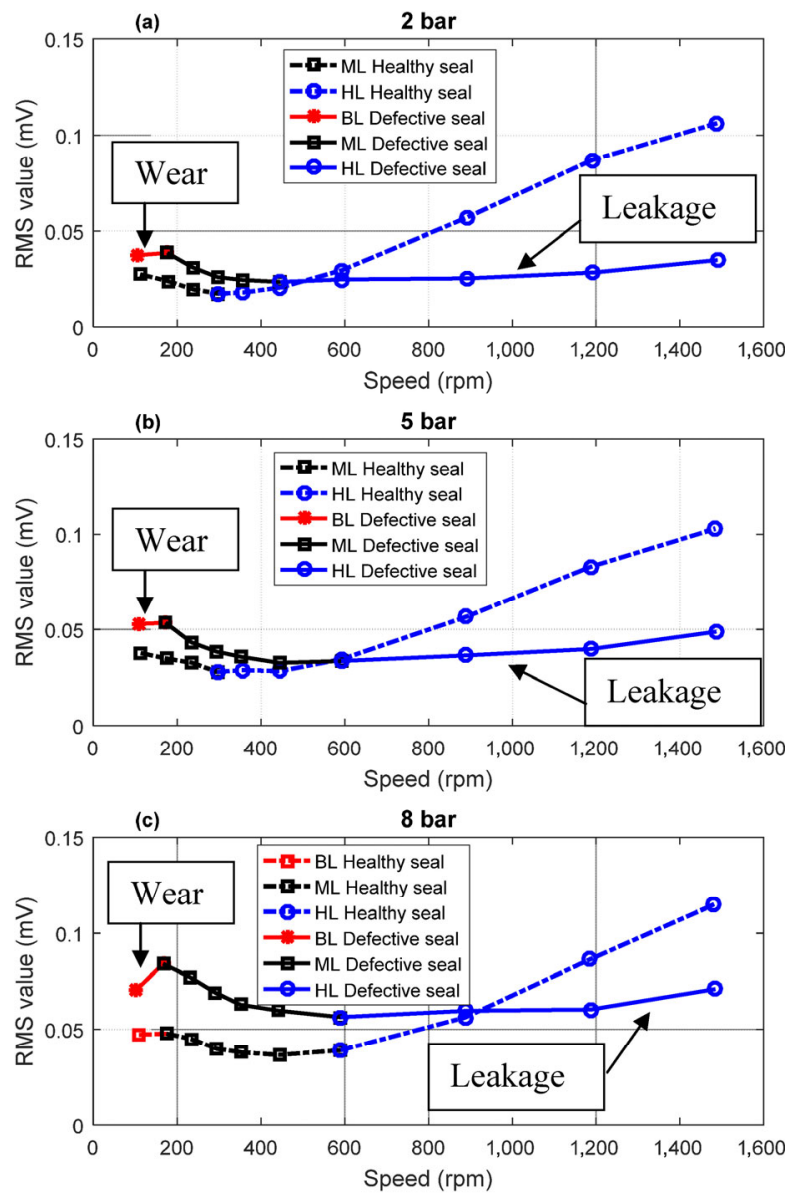

Fig. 14 The AE RMS values for healthy seal and defective seal test under different operating conditions. significantly. The most likely reason for the gap increase is thermally induced waviness caused by the cooler areas around the scratches versus region in between the scratches that generates higher hydrodynamic pressure lift up. Consequently, the RMS value of $\mathrm{AE}$ signals related to the defective seal testing becomes passive and does not show notable change by increasing the speed. Therefore, the power of sliding speed, depicted by one in Eq. (3), sees smaller values due to the failure of seal. This gives good evidence to detect the leakage which mainly refers to as the failure of mechanical seals. To see the power values of sliding speed that achieved experimentally, interested readers may refer to Ref. [31].

The difference between the healthy baseline and defective seal testing becomes more evident in $\mathrm{AE}$ spectra as shown in Fig. 15, e.g. compared to the results achieved at the speed of $450 \mathrm{rpm}$ in Fig. 14(a) and Fig. 14(b). However more robust signal processing techniques are needed to ensure fault conditions are separated reliably form the healthy baseline.

\section{Fault classification}

Based on the discussions made in Section 3.2 and Section 3.4, in few cases around transition point (e.g. at rotational speed of $450 \mathrm{rpm}$ for different sealed pressure settings), AE RMS value along with AE spectra analysis is not able to produce a clear separation of the faulty seal (i.e. dry running testing and defective seal testing) from the healthy baseline. Therefore, more advanced signal processing methods are needed to overcome this challenge.

Several studies demonstrate that attempts have been made for classifying of AE signals using various signal processing and pattern recognition techniques such as KS statistic [35], neural networks [14, 36, 37], genetic algorithm [14, 38, 39], and fuzzy logic [40].

In this section, an Auto-Regressive (AR) model is developed to classify AE signals recorded from the fault conditions of mechanical seals operating at the speed of $450 \mathrm{rpm}$ and under different pressure settings. This approach can also be applied to AE signals acquired from other speed and pressure settings.

AR modelling has been applied successfully for fault detection in different rotating machines such as 

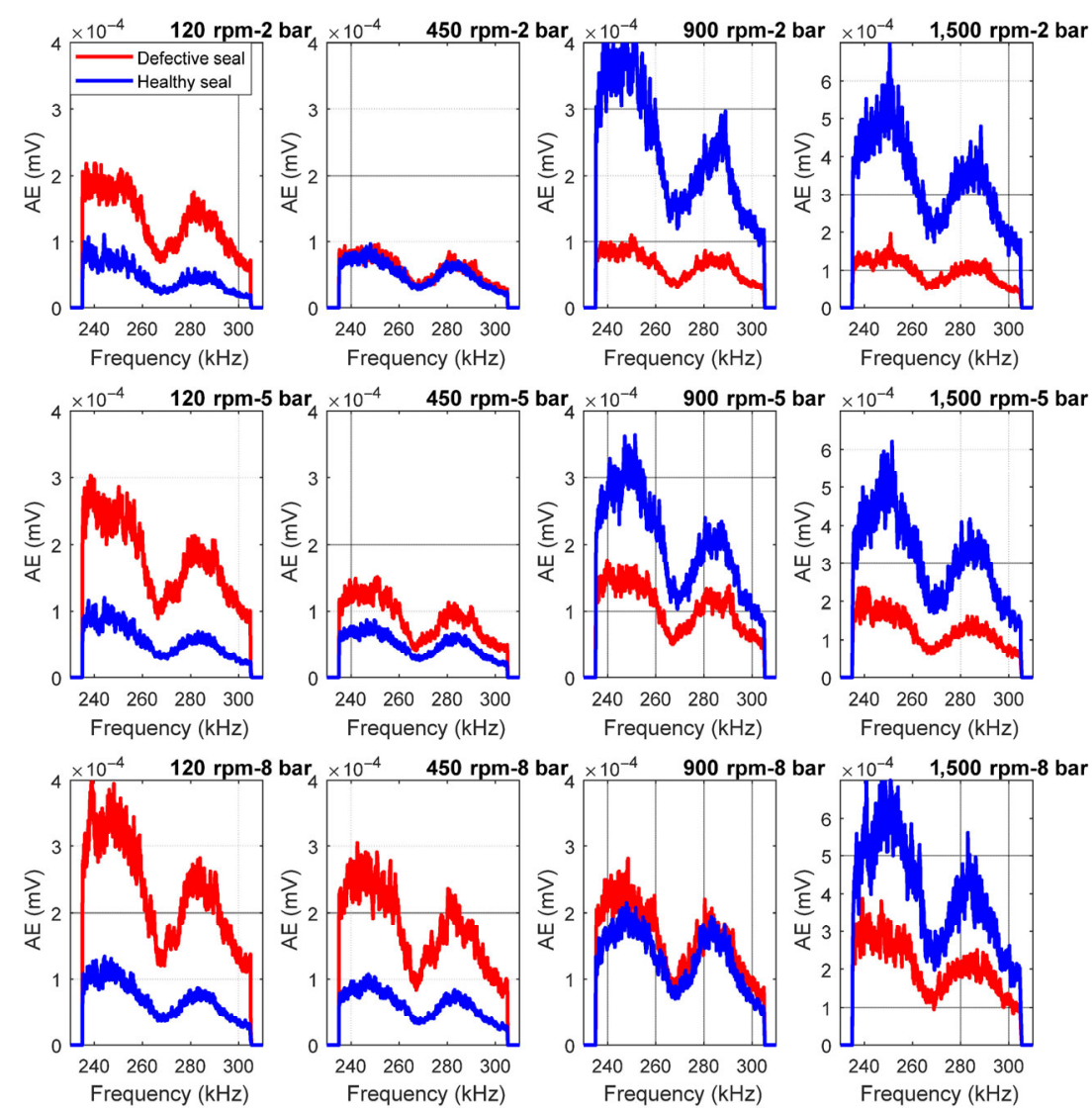

Fig. 15 AE spectra for healthy seal and defective seal testing under different operating conditions.

electrical motors [41], gears [42], and bearings [43]. An AR model is a mathematical technique used for polynomial curve-fitting of a particular signal and is defined as following:

$$
x_{i}=c_{1} x_{i-1}+c_{2} x_{i-2}+\ldots+c_{\alpha} x_{i-\alpha}+\varepsilon_{i}
$$

where $x_{\mathrm{i}} c_{1} \ldots c_{\alpha}, i, \alpha$ and $\varepsilon$ are signal sampled at regular intervals of time, auto-regression coefficients (weights), sample instances $(i=1, \ldots, \beta)$, order of the model and residual signal (that assumed to contain the output noise and an error component) respectively. A new value is therefore a linear combination of previous values plus the current noise. Therefore, Eq. (4) can be written in a matrix form as following:

$$
\left[\begin{array}{c}
x_{\alpha+1} \\
x_{\alpha+2} \\
\cdot \\
\cdot \\
\cdot \\
x_{\beta}
\end{array}\right]=\left[\begin{array}{cccc}
x_{\alpha} & x_{\alpha-1} & \ldots & x_{1} \\
x_{\alpha+1} & x_{\alpha} & \ldots & x_{2} \\
\cdot & \cdot & & \cdot \\
\cdot & \cdot & \ldots & \cdot \\
\cdot & \cdot & & \cdot \\
x_{\beta-1} & x_{\beta-2} & \ldots & x_{\beta-\alpha}
\end{array}\right]\left[\begin{array}{c}
c_{1} \\
c_{2} \\
\cdot \\
\cdot \\
\cdot \\
c_{\alpha}
\end{array}\right]+\left[\begin{array}{c}
\varepsilon_{\alpha+1} \\
\varepsilon_{\alpha+2} \\
\cdot \\
\cdot \\
\cdot \\
\varepsilon_{\beta}
\end{array}\right]
$$

In AR modelling, the number of model coefficients (or model order) selected for modelling of the recorded signal is a challenging problem. It is likely that a small number of coefficients will not be able to model the underlying trend in data, whilst if a very large number of coefficients are selected then it is possible the model could over-fit the data used to create it [41]. Thus, in the first step the optimised order of model should be determined. This can be achieved by plotting the magnitude of the last model coefficient against the model order [41, 44], as shown in Fig. 16.

By assessing the Fig. 16, a model of order 35 was selected for the recorded AE data in this research. The data reconstruction ability of a model of this size, over a short data segment, is illustrated in Fig. 17.

It is evident that the zero-valued AR model estimate between 0 and approximately 0.05 milliseconds, is due to the fact no modelling can take place until 35 data points are available.

An AR model developed on recorded AE (or vibration) signals from a machine represents the 


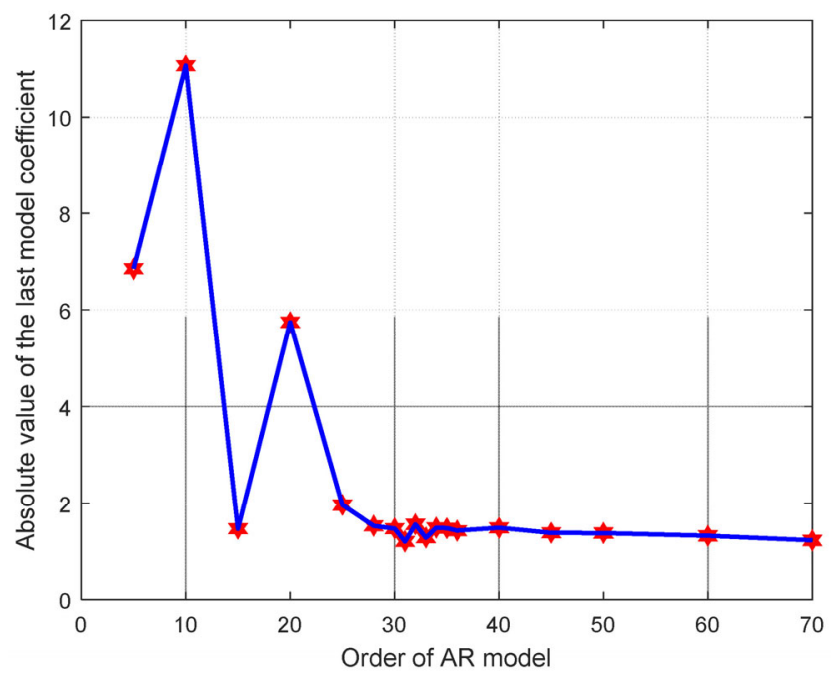

Fig. 16 Optimisation of AR model order.
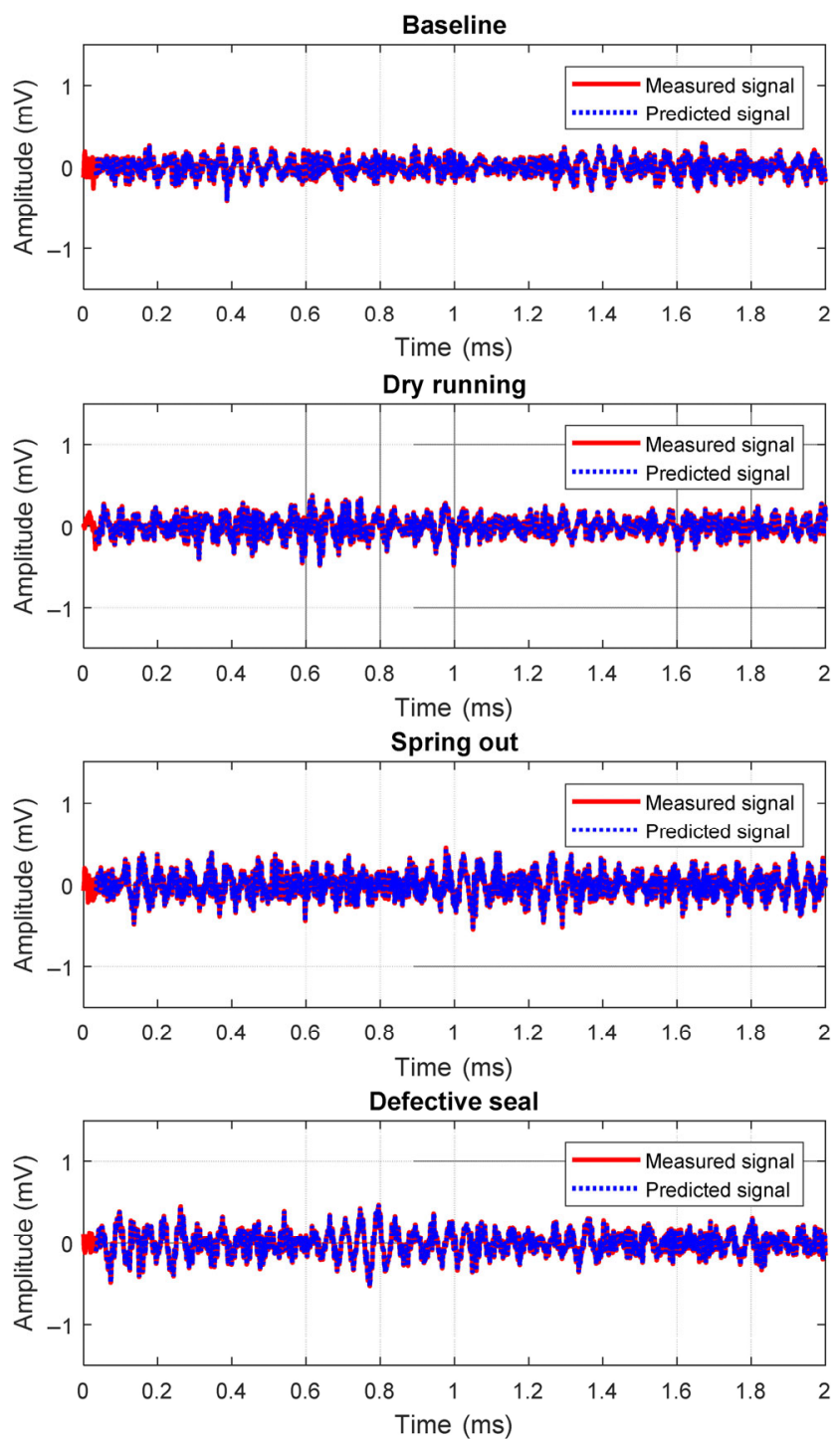

Fig. 17 Data reconstruction ability of a 35 order AR model. characteristics of that specific machine. When a new AR model is created on data recorded from the fault conditions, the AR coefficients will be different to those previously determined for the healthy baseline. Therefore the change in the coefficients, as an indicator of developing fault, can be used to monitor the integrity of the machine components.

To classify different faults, different coefficients of a unique AR model could be plotted against each other. Following examination of the different plots, the results for classifying of recorded AE signals at the speed of $450 \mathrm{rpm}$ and under different pressure settings are presented in Fig. 18-Fig. 20. It is immediately noted that the exploratory experiments in present work have shown that these coefficients are one of different possible combination of coefficients that leads to a clear separation between different cases. However, these coefficients are not unique and other coefficients may give approximately same results.

For each test 1,024 points are plotted since AR models were developed on segments of 2,048 data points from separate files of length 2,097,152.

As it is observed in Fig. 18-Fig. 20, the developed AR model allows a clear separation of the fault conditions from the healthy baseline. This gives a strong potential in order to develop more advanced AE based diagnostic technologies to improve the

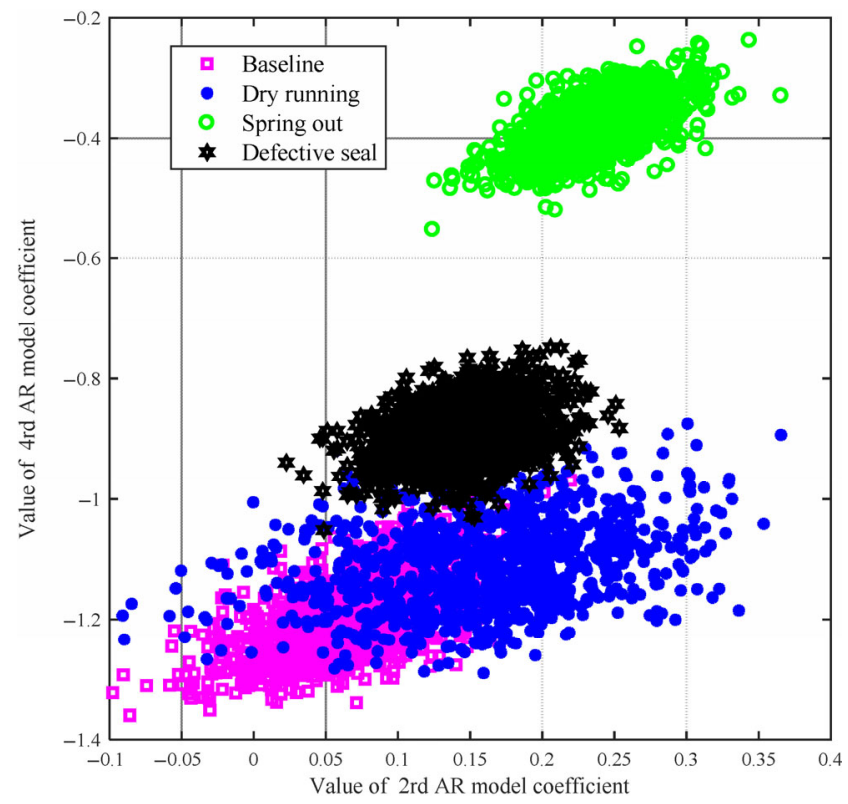

Fig. 18 Separation of different faults at speed of $450 \mathrm{rpm}$ and 2 bar sealed pressure. 


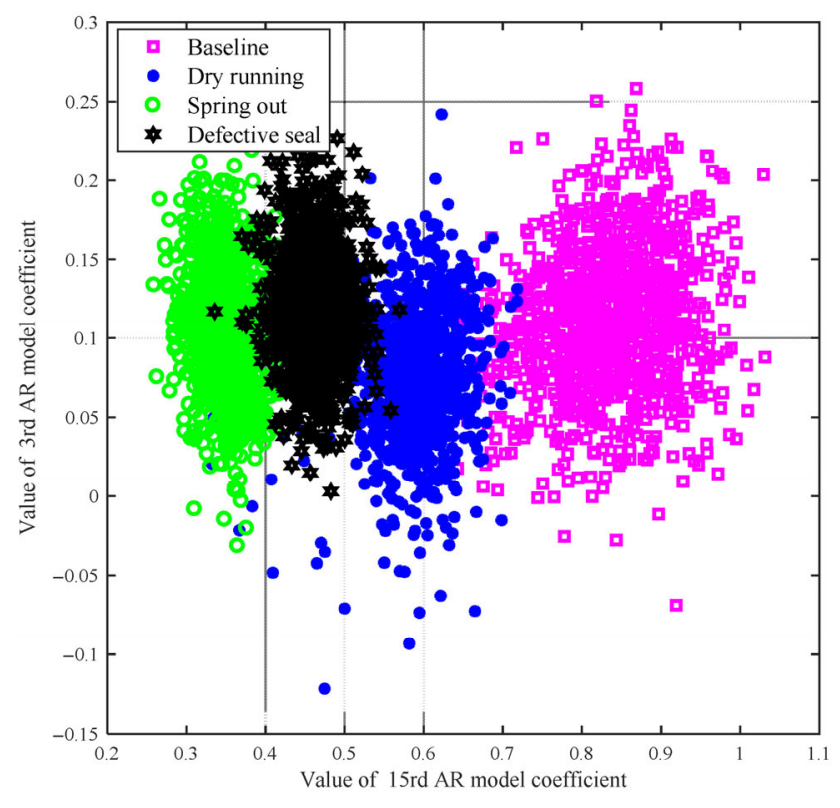

Fig. 19 Separation of different faults at speed of $450 \mathrm{rpm}$ and 5 bar sealed pressure.

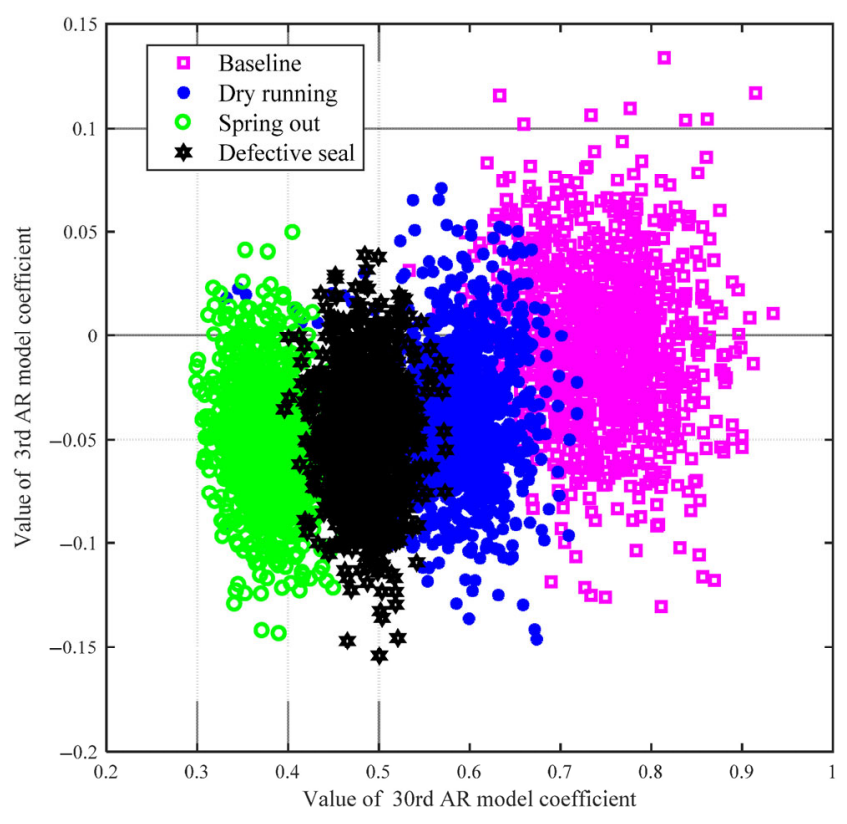

Fig. 20 Separation of different faults at speed of $450 \mathrm{rpm}$ and 8 bar sealed pressure.

reliability of rotating machines operating with mechanical seals.

\section{Conclusion}

This paper demonstrates the effectiveness of $\mathrm{AE}$ measurements to detect operating faults of mechanical seals at initial stages. To investigate the changes in AE signal parameters under different fault conditions and feasibility of predicting failure of mechanical seals at initial stages, an experimental study was carried out to simulate three main faults i.e. dry running, spring fault, and defective face (leakage) on a purpose built test rig. The analysis of results produces the following key points:

1) AE is generated by the tribological source mechanisms in the sealing gap. Based on the experimental study presented in this work, the frequency range of $270 \pm 35 \mathrm{kHz}$ can present the tribological behaviour of mechanical seals.

2) Analysis of the results of AE RMS value at constant sealed pressure shows a good sensitivity to the change of tribological regimes by the speed increase. Therefore, this speed dependency of AE RMS value allows different tribological regimes as well as fault conditions to be identified.

3) A significant difference was observed between AE RMS values from the healthy and faulty seals. It has been shown that RMS value of AE signals is very effective for fault detection at initial stage in mechanical seals.

4) Analysis of the results in frequency domain is in good agreement with analysis that has been carried out in time domain (AE RMS value). However, in some cases the frequency domain analysis gives better separation of faulty conditions from the healthy baseline.

5) In some speed and pressure settings around the transition point, AE RMS value and frequency domain analysis do not generate a notable response to distinguish fault conditions from the healthy baseline. Therefore, an auto regressive model has been developed for clustering different failure modes of mechanical seals and satisfactory results were perceived.

Open Access: The articles published in this journal are distributed under the terms of the Creative Commons Attribution 4.0 International License (http:// creativecommons.org/licenses/by/4.0/), which permits unrestricted use, distribution, and reproduction in any medium, provided you give appropriate credit to the original author(s) and the source, provide a link to the Creative Commons license, and indicate if changes were made. 


\section{References}

[1] Flitney B. Review of features in sealing technology during the last year. Sealing Technol 2005(5): 6-11 (2005)

[2] Su J J, Wei L, Gu B Q. Development course and research trend on the mechanical seal. Lubric Eng (4): 128-131, 134 (2004)

[3] Wei L, Gu B Q, Feng X, Sun J J. Research on friction characteristic of end faces of mechanical seals. In Advanced Tribology. Eds. Berlin, Heidelberg: Springer, 2009: 304-308.

[4] Fan Y E. Condition monitoring of mechanical seals using acoustic emissions. Doctoral dissertation. Manchester (UK): University of Manchester, 2007.

[5] Etsion I, Constantinescu I. Experimental observation of the dynamic behavior of noncontacting coned-face mechanical seals. ASLE Trans 27(3): 263-270 (1984)

[6] Green I. Real-time monitoring and control of mechanical face-seal dynamic behaviour. Sealing Technol 2001(96): 6-11 (2001)

[7] Anderson W, Jarzynski J, Salant R. Monitoring the condition of liquid-lubricated mechanical seals. Sealing Technol 2002(2): 6-11 (2002)

[8] Reddyhoff T, Dwyer-Joyce R, Harper P. Ultrasonic measurement of film thickness in mechanical seals. Sealing Technol 2006(7): 7-11 (2006)

[9] Kataoka T, Yamashina C, Komatsu M. Development of an incipient failure detection technique for mechanical seals. In Proceedings of 4th International Pump Symposium, Houston, Texas, 1987.

[10] Miettinen J, Siekkinen V. Acoustic emission in monitoring sliding contact behaviour. Wear 181-183: 897-900 (1995)

[11] Mba D, Roberts T, Taheri E, Roddis A. Application of acoustic emission technology for detecting the onset and duration of contact in liquid lubricated mechanical seals. Insight-Non-Destruct Test Condit Monitor 48(8): 486-487 (2006)

[12] Holenstein A P. Diagnosis of mechanical seals in large pumps. Sealing Technol 1996(33): 9-12 (1996)

[13] Towsyfyan H, Wei N S, Gu F S, Ball A. Identification of lubrication regimes in mechanical seals using acoustic emission for condition monitoring. In Proceedings of the 54th Annual Conference of the British Institute of Non-Destructive Testing BINDT 2015, Telford, UK, 2015.

[14] Sadegh H, Mehdi A N, Mehdi A. Classification of acoustic emission signals generated from journal bearing at different lubrication conditions based on wavelet analysis in combination with artificial neural network and genetic algorithm. Tribol Int 95: 426-434 (2016)
[15] Raharjo P, Abdusslam S A, Wang T, Gu F S, Ball A. An investigation of acoustic emission responses of a self aligning spherical journal bearing. In Proceedings of the 8th International Conference on Condition Monitoring and Machinery Failure Prevention Technologies CM/MFPT 2011, Cardiff, UK, 2011.

[16] Márquez F P G, Tobias A M, Pinar Pérez J M, Papaelias M. Condition monitoring of wind turbines: Techniques and methods. Renew Energy 46: 169-178 (2012)

[17] Purarjomandlangrudi A, Nourbakhsh G. Acoustic emission condition monitoring: An application for wind turbine fault detection. Int J Res Eng Technol 2(5): 907-918 (2013)

[18] Toutountzakis T, Tan C K, Mba D. Application of acoustic emission to seeded gear fault detection. NDT E Int 38(1): 27-36 (2005)

[19] Loutas T H, Sotiriades G, Kalaitzoglou I, Kostopoulos V. Condition monitoring of a single-stage gearbox with artificially induced gear cracks utilizing on-line vibration and acoustic emission measurements. Appl Acoust 70(9): 1148-1159 (2009)

[20] Rogers L M. The application of vibration signature analysis and acoustic emission source location to on-line condition monitoring of anti-friction bearings. Tribol Int 12(2): 51-58 (1979)

[21] Al-Ghamd A M, Mba D. A comparative experimental study on the use of acoustic emission and vibration analysis for bearing defect identification and estimation of defect size. Mechan Syst Signal Process 20(7): 1537-1571 (2006)

[22] Towsyfyan H. Investigation of the nonlinear tribological behaviour of mechanical seals for online condition monitoring. $\mathrm{PhD}$ thesis. Huddersfield (UK): University of Huddersfield, 2017.

[23] Lubbinge H. On the lubrication of mechanical face seals. $\mathrm{PhD}$ thesis. Enschede (The Netherlands): Universiteit Twente, 1999.

[24] Sinou J J, Cayer-Barrioz J, Berro H. Friction-induced vibration of a lubricated mechanical system. Tribol Int 61: 156-168 (2013)

[25] Akay A. Acoustics of friction. J Acoust Soc Amer 111(4): 1525-1548 (2002)

[26] Fan Y B, Gu F S, Ball A. Modelling acoustic emissions generated by sliding friction. Wear 268(5-6): 811-815 (2010)

[27] Sharma R B,Parey A. Modelling of acoustic emission generated in rolling element bearing. Appl Acoust (2017) doi: 10.1016/j.apacoust. 2017.07.015 (in press)

[28] Benabdallah H S, Aguilar D A. Acoustic emission and its relationship with friction and wear for sliding contact. Tribol Trans 51(6): 738-747 (2008) 
[29] Wang L,Wood R J K. Acoustic emissions from lubricated hybrid contacts. Tribol Int 42(11-12): 1629-1637 (2009)

[30] Huang W F, Lin Y B, Gao Z, Fan W J, Suo S F, Wang Y M. An acoustic emission study on the starting and stopping processes of a dry gas seal for pumps. Tribol Lett 49(2): 379-384 (2013)

[31] Towsyfyan H, Gu F S, Ball A D, Liang B. Modelling acoustic emissions generated by tribological behaviour of mechanical seals for condition monitoring and fault detection. Tribol Int 125: 46-58 (2018)

[32] Vezjak A,Vizintin J. Experimental study on the relationship between lubrication regime and the performance of mechanical seals. Lubricat Eng 57(1): 17-22 (2001)

[33] Flitney R K. Seals and Sealing Handbook. Oxford (UK): Elsevier, 2011.

[34] Buck G S. The role of hydraulic balance in mechanical pump seals. In Proceedings of the 7th Turbomachinery Symposium, Texas A\&M University, USA, 1978.

[35] Hall L D, Mba D. Acoustic Emissions diagnosis of rotorstator rubs using the KS statistic. Mechan Syst Signal Process 18(4): 849-868(2004)

[36] Li C J, Wu S M. On-line detection of localized defects in bearings by pattern recognition analysis. J Eng Ind 111(4): 331-336(1989),

[37] Yan T, Holford K M, Carter D, Brandon J. Classification of acoustic emission signatures using a self-organization

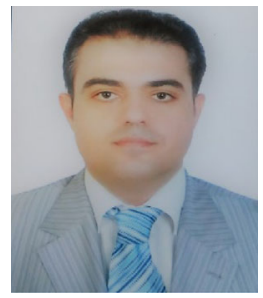

Hossein TOWSYFYAN. He received his Ph.D. degree in mechanical engineering from the University of Huddersfield, United Kingdom, in 2017. Now he is a postdoctoral researcher at the University of

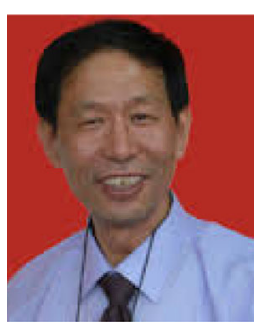

Fengshou GU. He is an expert in the fields of vibro-acoustics analysis and machinery diagnosis, with over 20 years of research experience. Now he is a principal research fellow at the the University of Huddersfield, neural network. $J$ Acoust Emiss 17(1-2): 49-59 (1999)

[38] Suresh S, Omkar S N, Mani V, Menaka C. Classification of acoustic emission signal using genetic programming. $J$ Aerosp Sci Technol 56(1): 26-41 (2004)

[39] Sibil A, Godin N, R'Mili M, Maillet E, Fantozzi G. Optimization of acoustic emission data clustering by a genetic algorithm method. J Nondestruct Eval 31(2): 169-180 (2012)

[40] Baqqar M, Tran V T, Gu F S, Ball A. Comparison between adaptive neuro-fuzzy inference system and general regression neural networks for gearbox fault detection using motor operating parameters. In Proceedings of Computing and Engineering Annual Researchers' Conference 2013: CEARC'13, Huddersfield, 2013: 118-126.

[41] Payne B S. Condition monitoring of electrical motors for improved asset management. Ph.D Thesis. Manchester (UK): University of Manchester, 2003.

[42] Wang W Y, Wong A K. Autoregressive model-based gear fault diagnosis. J Vibr Acoust 124(2): 172-179 (2002)

[43] Baillie D C, Mathew J. A comparison of autoregressive modeling techniques for fault diagnosis of rolling element bearings. Mechan Syst Signal Process 10(1): 1-17 (1996)

[44] Box G E P, Jenkins G M, Reinsel G C, Ljung G M. Time Series Analysis: Forecasting and Control. New Jersey (USA): Prentice Hall, 1994.

Southampton, in the Institute of Sound and Vibration Research (ISVR). His research interest includes tribology, condition monitoring, advanced nondestructive testing methods, artificial intelligence and digital signal and image processing.

United Kingdom. His research interest includes machine dynamics, advanced signal processing, tribology dynamic responses, condition monitoring, measurement systems and sensor development, artificial intelligence and related fields. 


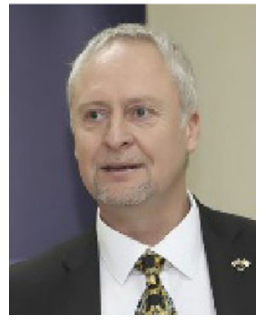

Andrew D BALL. He took the Shell sponsored lectureship in maintenance engineering at the University of Manchester in 1991 and was promoted to professor of maintenance engineering in 1999. He was the head of School of the Manchester School of Engineering from 2003 to 2004 and in 2005 he became dean of Graduate Education. In late-2007 he moved to the University of Huddersfield as professor of diagnostic engineering and pro-vice-chancellor for research and enterprise. His research expertise is in the detection and diagnosis of faults in mechanical, electrical and

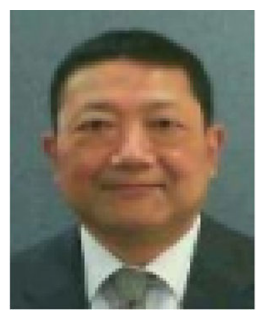

Bo LIANG. He received his BEng and MPhil from Harbin Engineering University (China) in 1982 and 1985, respectively. He got his $\mathrm{PhD}$ degree from University of Manchester (UK) electro-hydraulic machines, in data analysis and signal processing, and in measurement systems and sensor development. He is the author of over 300 technical and professional publications, and he has spent a large amount of time lecturing and consulting to industry in all parts of the world. He has to date graduated almost 100 research degrees, in the fields of mechanical, electrical and diagnostic engineering. He has acted as external examiner at over 30 overseas institutions, he holds visiting and honorary positions at 4 overseas universities, he sits on 3 large corporate scientific advisory boards, and he is also a registered expert witness in 3 countries.

in 2000. Dr. Bo Liang currently is a reader at University of Huddersfield (UK). His research interests are vibration analysis and control, vehicle dynamics, artificial intelligence, condition monitoring and fault diagnosis. 